\title{
Erratum to: Surgical correction of isolated unilateral absence of right pulmonary artery
}

\author{
Takeshi Hiramatsu $\cdot$ Shigeru Komori $\cdot$ \\ Yoshitaka Okamura • Hiroyuki Suzuki • \\ Takashi Takeuchi $\cdot$ Syoichi Shibuta
}

Published online: 28 October 2010

(C) Springer 2010
S. Komori · Y. Okamura

Department of Thoracic and Cardiovascular Surgery, Wakayama Medical University, Wakayama, Japan

H. Suzuki · T. Takeuchi · S. Shibuta

Department of Pediatrics, Wakayama Medical University, Wakayama, Japan

The online version of the original article can be found under doi:10.1007/s00380-009-1207-5.

T. Hiramatsu $(\bowtie)$

Department of Cardiovascular Surgery,

Tokyo Women's Medical University,

8-1 Kawada-cho, Shinjuku-ku,

Tokyo 162-8666, Japan

e-mail: shiramat@hij.twmu.ac.jp

S. Komori · Y. Okamura

Department of Thoracic and Cardiovascular Surgery,

Wakayama Medical University, Wakayama, Japan

H. Suzuki · T. Takeuchi - S. Shibuta

Department of Pediatrics, Wakayama Medical University,

Wakayama, Japan 